07

\title{
Особенности упрочнения структурированного интенсивной пластической деформацией сплава $\mathrm{Al}-\mathrm{Cu}-\mathrm{Zr}$
}

\author{
(C) Т.С. Орлова ${ }^{1}$, Д.И. Садыков ${ }^{2}$, М.Ю. Мурашкин ${ }^{3,4}$, В.У. Казыханов ${ }^{3}$, Н.А. Еникеев ${ }^{3,4}$ \\ ${ }^{1}$ Физико-технический институт им. А.Ф. Иофрфе РАН, \\ Санкт-Петербург, Россия \\ ${ }^{2}$ Санкт-Петербургский национальный исследовательский университет \\ информационных технологий, механики и оптики, \\ Санкт-Петербург, Россия \\ ${ }^{3}$ Уфимский государственный авиационный технический университет \\ Институт фризики перспективных материалов, \\ Уфра, Россия \\ ${ }^{4}$ Санкт-Петербургский государственный университет, \\ Санкт-Петербург, Россия \\ E-mail: orlova.t@mail.ioffe.ru
}

Поступила в Редакцию 5 мая 2021 г.

В окончательной редакции 5 мая 2021 г.

Принята к публикации 7 мая 2021 г.

Исследовано влияние малых добавок меди на микроструктуру и физико-механические свойства ультрамелкозернистого сплава $\mathrm{Al}-1.47 \mathrm{Cu}-0.34 \mathrm{Zr}$ (wt.\%), структурированного интенсивной пластической деформацией кручением после предварительного отжига при температуре $375^{\circ} \mathrm{C}$ в течение $140 \mathrm{~h}$. В результате обработки достигнуты высокие значения прочностных характеристик (условный предел текучести $430 \mathrm{MPa}$, предел прочности $574 \mathrm{MPa}$ ) при приемлемом уровне электропроводности (46.1\% IACS) и пластичности (относительное удлинение до разрушения $\sim 5 \%$ ). С учетом микроструктурных параметров, определенных методами рентгеноструктурного анализа и просвечивающей электронной микроскопии, проведен анализ действующих механизмов упрочнения, обеспечивающих такую высокую прочность. Показано, что ключевую роль в упрочнении играет $\mathrm{Cu}$. Добавка меди способствует значительному измельчению зерна и, как следствие, увеличивает зернограничное упрочнение. Кроме того, легирование медью приводит к значительному дополнительному упрочнению $(\sim 130 \mathrm{MPa})$ в ультрамелкозернистом сплаве, нетипичному для крупнозернистого состояния. Наиболее вероятными причинами такого упрочнения могут быть сегрегация $\mathrm{Cu}$ на границах зерен и формирование нанокластеров $\mathrm{Cu}$.

Ключевые слова: алюминиевые сплавы, интенсивная пластическая деформация, микроструктура, механизмы упрочнения, электропроводность.

DOI: 10.21883/FTT.2021.10.51408.104

\section{1. Введение}

Проводниковые сплавы на основе алюминия широко применяются в различных отраслях промышленности в силу хорошего сочетания таких физико-технических характеристик как высокая электропроводность, коррозионная стойкость, легкость и нетоксичность в различных соединениях с другими металлами. Однако, несмотря на широкую распространенность алюминиевых сплавов, для современных применений в электротехнической промышленности требуются материалы, обладающие не только высокой электропроводностью, но также и высокой прочностью, в том числе и при повышенных температурах. Алюминиевые сплавы, легированные 0.1-0.4 wt.\% Zr, показали хорошие результаты в обеспечении термостабильности прочностных характеристик и электропроводности $[1,2]$. Повышение термостабильности сплавов $\mathrm{Al}-\mathrm{Zr}$ достигалось, в первую очередь, путем их длительных отжигов при температурах $300-450^{\circ} \mathrm{C}$, приводящих к образованию наноразмерных частиц мета- стабильной фазы $\mathrm{Al}_{3} \mathrm{Zr}\left(\mathrm{L1}_{2}\right)$ [3-5]. Происходящее при этом очищение решетки алюминия от атомов легирующих элементов приводила к значительному повышению электропроводности. Однако эти сплавы сильно уступают в прочности как медным проводникам, так и широко используемым в электротехнике сплавам системы $\mathrm{Al}-\mathrm{Mg}-\mathrm{Si}$ [6]. Одним из наиболее эффективных способов повышения прочностных характеристик многих металлов и сплавов является структурирование их интенсивной пластической деформацией (ИПД). В первую очередь, упрочнение после ИПД связано с измельчением зерна, увеличением плотности дефектов кристаллической решетки, изменением распределения границ зерен (ГЗ) по разориентировкам, формированием дисперсных частиц вторичных фаз [7-10]. Однако степень увеличения прочности после обработки ИПД может заметно отличаться как у различных сплавов, так и для одного и того же сплава в зависимости от его исходного состояния (до обработки ИПД). Исследование 
влияния интенсивной пластической деформации кручением (ИПДК) на сплав $\mathrm{Al}-0.4 \mathrm{Zr}$ (wt.\%) в различных исходных состояниях [11-13] показало незначительный рост его прочностных характеристик, в то время как выполненная в аналогичном режиме деформация сплава $\mathrm{Al}-0.53 \mathrm{Mg}-0.27 \mathrm{Zr}$ (wt.\%) [14] привела к колоссальному увеличению прочности: к изменению предела текучести и предела прочности соответственно в 3.4 и 3.0 раза. Показано, что малая добавка $\mathrm{Mg}$ (0.53 wt.\% или соответственно 0.6 at.\%) способствует сильному измельчению зерна и, следовательно, значительно увеличивает зернограничное упрочнение. Кроме того, для ультрамелкозернистого (УМЗ) сплава $\mathrm{Al}-0.53 \mathrm{Mg}-0.27 \mathrm{Zr}$ было выявлено действие дополнительных, нетипичных для крупнозернистого состояния механизмов упрочнения [14].

Известно, что легирование медью даже в небольших количествах также способствует измельчению зеренной структуры [15-18] и значительному повышению прочности [15] алюминиевых сплавов $\mathrm{Al}-\mathrm{Cu}$ в результате воздействия ИПД. Влияние ИПДК на микроструктуру сплавов $\mathrm{Al}-\mathrm{Cu}$ изучалось в ряде работ [15-20]. В работе [18] было показано, что обработка ИПДК даже при комнатной температуре сплава с 0.83 at.\% $\mathrm{Cu}$, находящейся исходно в твердом растворе, приводит к формированию преимущественно стабильных частиц $\theta$-фазы $\left(\mathrm{Al}_{2} \mathrm{Cu}\right)$ на границах зерен. На ГЗ также были выявлены сегрегации с концентрацией атомов $\mathrm{Cu}$, в несколько раз превышающей таковую в объеме зерен. Однако изучению влияния таких сегрегаций на упрочнение сплавов $\mathrm{Al}-\mathrm{Cu}$ не уделялось достаточного внимания. Выделение частиц $\theta$-фазы на границах зерен и в тройных стыках наблюдалось также в сплавах $\mathrm{Al}-2 \mathrm{Cu}$ (wt.\%) [17] и $\mathrm{Al}-5 \mathrm{Cu}$ (wt.\%) [19] после обработки ИПД. Растворение предварительно выделенной $\theta^{\prime}$-фазы с последующим формированием частиц $\theta$-фазы преимущественно на ГЗ наблюдалось для сплавов $\mathrm{Al}-\mathrm{Cu}$ в результате ИПД [20,21].

В настоящей работе впервые исследовалось влияние ИПДК при комнатной температуре на микроструктуру, механические свойства и электропроводность предварительно отожженного (состаренного) при температуpe $375^{\circ} \mathrm{C}$ в течение $140 \mathrm{~h}$ сплава $\mathrm{Al}-1.47 \mathrm{Cu}-0.34 \mathrm{Zr}$ (wt.\%, 1.47 wt.\% Cu соответствует 0.63 at.\% Cu). Полученные характеристики сравниваются с аналогичными характеристиками, полученными для сплава $\mathrm{Al}-0.4 \mathrm{Zr}$ (wt.\%) без добавки $\mathrm{Cu}$ и сплава $\mathrm{Al}-0.53 \mathrm{Mg}-0.27 \mathrm{Zr}$ (wt.\%) с близкой по величине атомной концентрацией $\mathrm{Mg}$ (0.6 at.\%), также прошедших подобную обработку: старение и ИПДК-структурирование. Было показано, что структурирование сплава методом ИПДК приводит к колоссальному росту прочностных характеристик (микротвердости, предела текучести и предела прочности) при сохранении приемлемого уровня пластичности и электропроводности. В сплаве с УМЗ-структурой, полученной в результате обработки ИПДК, выявлено действие дополнительных, нетипичных для крупнозер- нистого состояния механизмов упрочнения, связанных с легированием медью.

\section{2. Образцы и экспериментальные методики}

В работе исследовался сплав $\mathrm{Al}-1.47 \mathrm{Cu}-0.34 \mathrm{Zr}$ (wt.\%), полный химический состав которого представлен в табл. 1. Первоначально сплав были получен в виде прутков диаметром $22 \mathrm{~mm}$ методом литья и последующей холодной прокатки, после которой диаметр прутков составил $14.5 \mathrm{~mm}$. Данное состояние сплава, здесь и далее обозначено как $\mathrm{Al}-\mathrm{Cu}-\mathrm{Zr}$ _Initial.

Далее для формирования равновесной структуры был проведен длительный отжиг сплава при температуре $375^{\circ} \mathrm{C}$ в течение $140 \mathrm{~h}$ (далее старение). Данное состояние сплава здесь и далее обозначено как $\mathrm{Al}-\mathrm{Cu}-\mathrm{Zr} \_\mathrm{AG}$. Для получения ультрамелкозернистой структуры часть материала $\mathrm{Al}-\mathrm{Cu}-\mathrm{Zr}$ _AG была обработана методом ИПДК. Обработка ИПДК проводилась на прессе Walter Klement GmbH HPT-07 при давлении в 6 GPa и количестве оборотов $n=10$. Для деформационной обработки были вырезаны образцы цилиндрической формы диаметром $14.5 \mathrm{~mm}$ и высотой $3 \mathrm{~mm}$. После ИПДК образцы имели форму дисков диаметром $\sim 20 \mathrm{~mm}$ и толщиной $\sim 1 \mathrm{~mm}$. Степень истинной деформации $e$ на расстоянии $5 \mathrm{~mm}$ от центра диска составила $\sim 6.6$ [9]. Данное состояние сплава здесь и далее обозначено как $\mathrm{Al}-\mathrm{Cu}-\mathrm{Zr} \_\mathrm{AG} \_\mathrm{HPT}$.

Микроструктура полученных образцов исследовалась методами рентгеноструктурного анализа (РСА), просвечивающей электронной микроскопии (ПЭМ) и просвечивающей растровой (сканирующей) электронной микроскопии (ПРЭМ).

Исследование структуры методом РСА осуществлялось с использованием дифрактомера Bruker D8 DISCOVER с фокусировкой по Брэггу-Брентано. Основные микроструктурные параметры: параметр решетки $a$, уровень микроискажений кристаллической решетки $\left\langle\varepsilon^{2}\right\rangle^{1 / 2}$, средний размер областей когерентного рассеяния $D_{X R D}$ определялись уточнением рентгенограмм методом Ритвельда с использованием программного обеспечения MAUD [22]. Плотность дислокаций определялась по формуле [23]:

$$
L_{d i s}=\frac{2 \sqrt{3}\left\langle\varepsilon^{2}\right\rangle^{1 / 2}}{D_{X R D} b}
$$

где $b-$ модуль вектора Бюргерса $(0.286 \mathrm{~nm})$.

Исследования методом ПЭМ проводились на микроскопе JEOL JEM 2100 при ускоряющем напряжении

Таблица 1. Химический состав сплава $\mathrm{Al}-1.47 \mathrm{Cu}-0.34 \mathrm{Zr}$. Содержание элементов приведено в wt.\%

\begin{tabular}{c|c|c|c|c|c|c}
\hline $\mathrm{Al}$ & $\mathrm{Cu}$ & $\mathrm{Zr}$ & $\mathrm{Si}$ & $\mathrm{Zn}$ & $\mathrm{V}$ & Остальное \\
\hline 98.1 & 1.47 & 0.34 & 0.04 & 0.014 & 0.01 & $\sim 0.03$
\end{tabular}




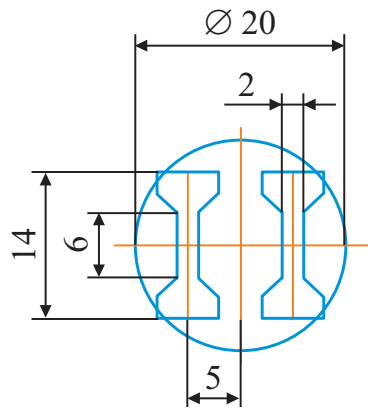

Рис. 1. Схема вырезки образцов для испытания на одноосное растяжение.

$200 \mathrm{kV}$. Фольги для наблюдений в ПЭМ получали механической полировкой с последующей двухструйной электрополировкой с использованием раствора азотной кислоты $(25 \%)$ в метаноле при $-25^{\circ} \mathrm{C}$ и рабочем напряжении $25 \mathrm{~V}$. Анализ микроструктуры (размер зерна, размер выделений вторичных фаз и т.д.) проводился с использованием ПО Fiji.

Исследования методом ПРЭМ осуществляли на микроскопе Zeiss Libra 200FE с ускоряющим напряжением $200 \mathrm{kV}$, оснащенном приставкой для проведения in-situ энергодисперсионной рентгеновской спектроскопии (ЭДС). Темнопольные изображения в сканирующем просвечивающем микроскопе были получены с использованием широкоуглового кругового детектора темного поля (high-angle annular dark-field, HAADF). Исследования методом ЭДС были проведены с пробой размером $20 \mathrm{~nm}$.

Механические свойства изучались путем проведения испытаний на одноосное растяжение и измерения микротвердости. Для проведения механических испытаний образцов, прошедших обработку ИПДК, из полученных дисков были вырезаны образцы в форме лопатки с шириной рабочей части $\sim 2 \mathrm{~mm}$ и длиной $\sim 6 \mathrm{~mm}$. Схема вырезки образцов приведена на рис. 1.

Испытания на одноосное растяжение проводились на испытательной машине Shimadzu AG-50kNX с постоянной скоростью деформации $5 \cdot 10^{-4} \mathrm{~s}^{-1}$. Деформация образцов измерялась с помощью видеоэкстензометра TRViewX 55S. Для каждого состояния (Al- $\mathrm{Cu}-$ $\mathrm{Zr}$ _Initial, $\left.\mathrm{Al}-\mathrm{Cu}-\mathrm{Zr} \_\mathrm{AG}, \mathrm{Al}-\mathrm{Cu}-\mathrm{Zr} \_\mathrm{AG} \_\mathrm{HPT}\right)$ испытывалось не менее трех образцов. На основании полученных деформационных кривых были определены условный предел текучести $\sigma_{0.2}$, предел прочности $\sigma_{U T S}$ и относительное удлинение до разрушения $\delta$.

Микротвердость $H_{V}$ образцов измерялась по методу Виккерса на микротвердомере Shimadzu HMV-G21DT с величиной нагрузки $100 \mathrm{~g}$, время нагрузки составляло $10 \mathrm{~s}$. Для каждого образца среднее значение микротвердости определялось на базе не менее двенадцати измерений.

Электропроводность $\omega$ измерялась при комнатной температуре с использованием вихретокового измери- теля электропроводности цветных металлов и сплавов ВЭ-27НЦ с точностью $\pm 2 \%$. Для перевода полученных значений электропроводности из единиц измерения $\mathrm{MS} / \mathrm{m}$ в \%IACS использовалась следующая формула:

$$
\% \mathrm{IACS}=\frac{\omega_{\text {Alloy }}}{\omega_{\mathrm{Cu}}} \cdot 100 \%,
$$

$\omega_{\mathrm{Cu}}-$ электропроводность отожженной меди $(58.0 \mathrm{MS} / \mathrm{m}), \omega_{\text {Alloy }}$ - электропроводность исследуемого алюминиевого сплава (MS/m).

\section{3. Экспериментальные результаты}

\section{1. Исследование микроструктуры}

Типичные ПЭМ-изображения микроструктуры сплава $\mathrm{Al}-\mathrm{Cu}-\mathrm{Zr}$ во всех трех состояниях представлены на рис. 2-5. В исходном состоянии (Al-Cu-Zr_Initial), полученном литьем и последующей холодной прокаткой, формировалась структура со средним размером зерна $617 \mathrm{~nm}$ (рис. 2, табл. 2). Подобная структура наблюдалась ранее в исходном состоянии сплава $\mathrm{Al}-0.4 \mathrm{Zr}$ (wt.\%), полученном комбинированным методом литья и прокатки $[11,12]$, а также в исходном состоянии сплава $\mathrm{Al}-0.53 \mathrm{Mg}-0.27 \mathrm{Zr}$ (wt.\%), полученном литьем с последующей горячей прокаткой [14].

После длительного отжига (старения) размер зерна практически не изменился: в состоянии $\mathrm{Al}-\mathrm{Cu}-\mathrm{Zr} \_\mathrm{AG}$ он составил $D_{a v}^{G} \approx 631 \mathrm{~nm}$. Микроструктура сплава в состоянии $\mathrm{Al}-\mathrm{Cu}-\mathrm{Zr} \_\mathrm{AG}$ характеризуется большим количеством наноразмерных преципитатов вторичной фазы (рис. 3, $a-c)$. Эти частицы расположены как внутри зерен, так и вдоль границ зерен и принадлежат метастабильной фазе $\mathrm{Al}_{3} \mathrm{Zr}\left(\mathrm{Ll}_{2}\right)$, что подтверждается исследованиями микродифракции (рис. 3,c). Известно [4,11,24-26], что длительный отжиг сплавов $\mathrm{Al}-\mathrm{Zr}$ при температурах в диапазоне $350-450^{\circ} \mathrm{C}$ является наиболее эффективным способом формирования наночастиц метастабильной фазы $\mathrm{Al}_{3} \mathrm{Zr}\left(\mathrm{L1}_{2}\right)$, которые способствуют повышению термостабильности прочностных

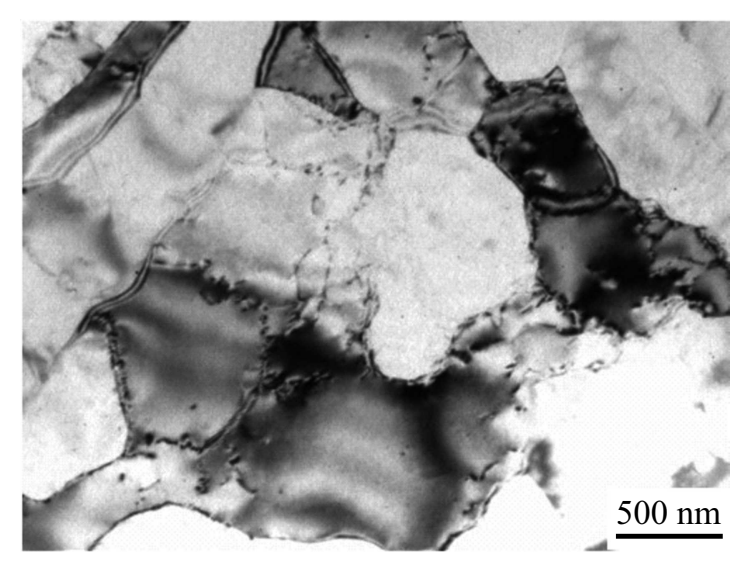

Рис. 2. ПЭМ-изображение микроструктуры сплава $\mathrm{Al}-\mathrm{Cu}-\mathrm{Zr}$ в состоянии Initial. 

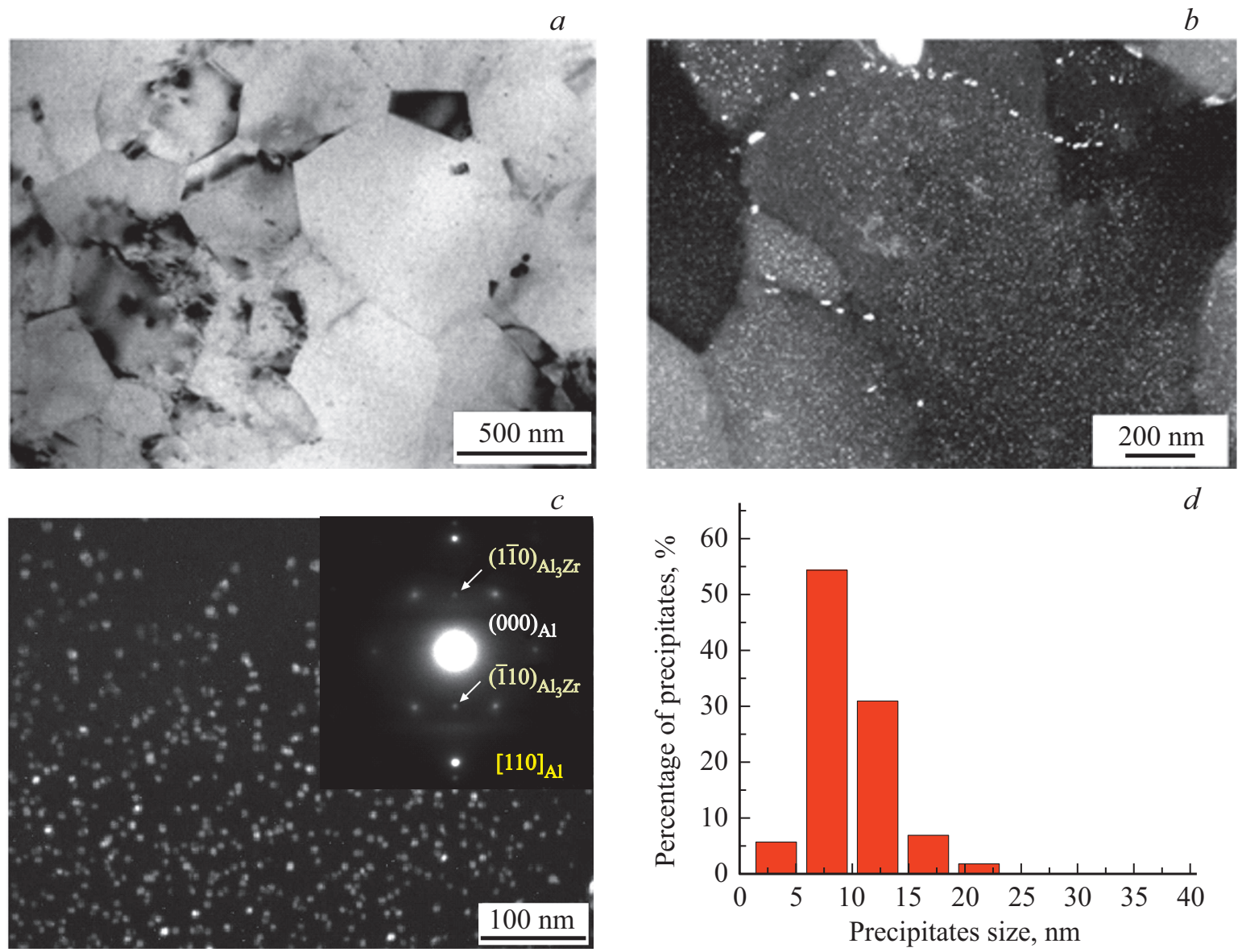

Рис. 3. ПЭМ-изображения микроструктуры сплава $\mathrm{Al}-\mathrm{Cu}-\mathrm{Zr}$ в состоянии $\mathrm{AG}$ в светлопольном $(a)$ и темнопольном $(b, c)$ режимах с картиной микродифракции (ось зоны [110] $\mathrm{Al})(c)$, а также распределение малых частиц фазы $\mathrm{Al}_{3} \mathrm{Zr}$ по размеру $(d)$.
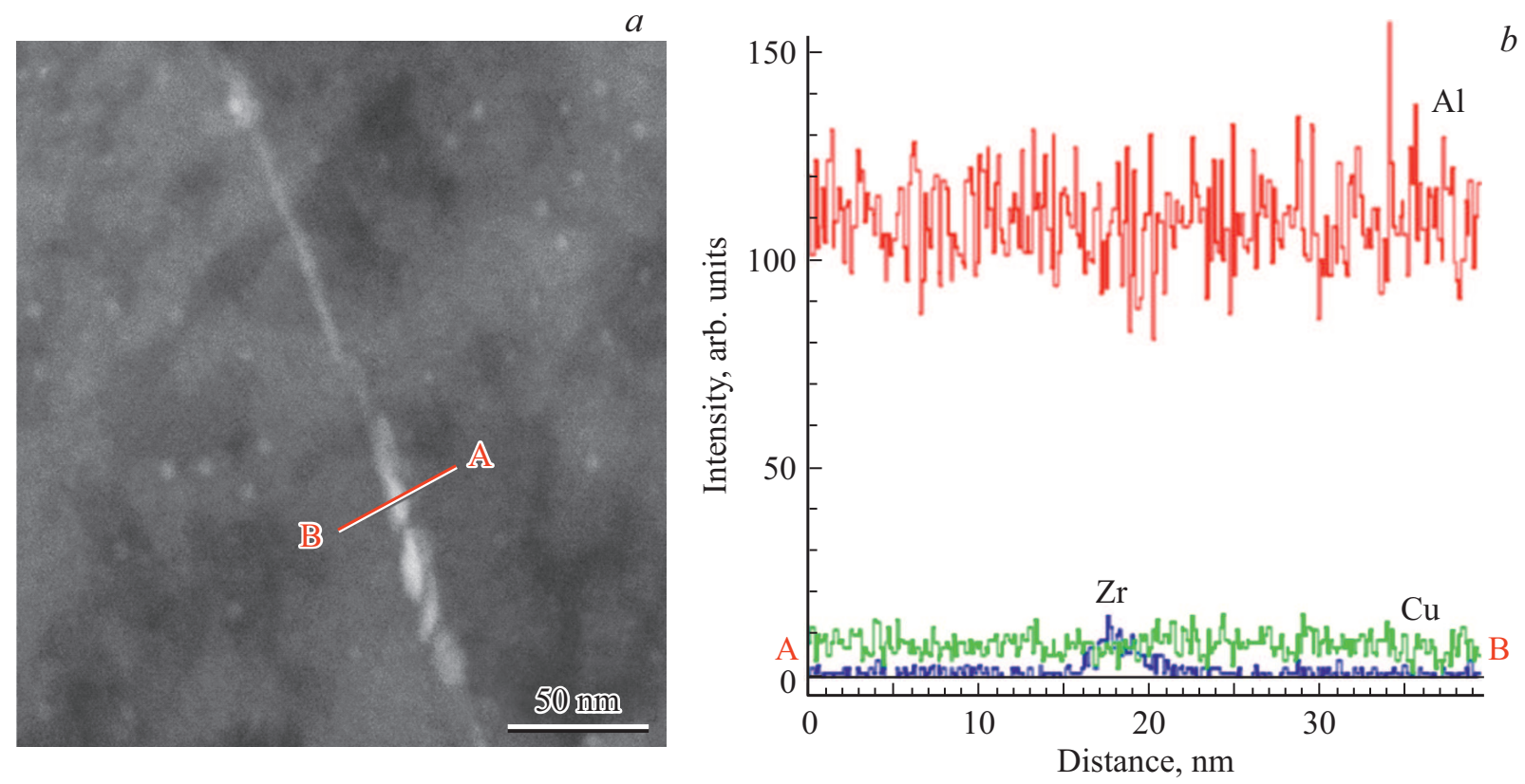

Рис. 4. ПРЭМ-изображение $(a)$ и ЭДС-анализ $(b)$ вдоль линии $\mathrm{AB}$, обозначенной на $(a)$, для сплава $\mathrm{Al}-\mathrm{Cu}-\mathrm{Zr}$ в состоянии $\mathrm{AG}$. 
Таблица 2. Параметры микроструктуры, полученные методами РСА и ПЭМ

\begin{tabular}{|c|c|c|c|c|c|c|}
\hline $\begin{array}{c}\text { Материал } \\
\text { (состояние) }\end{array}$ & $D_{a v}^{G}, \mathrm{~nm}$ & $a, \AA$ & $D_{X R D}, \mathrm{~nm}$ & $\langle\varepsilon 2\rangle^{1 / 2}, \%$ & $L_{d i s} \times 10^{13}, \mathrm{~m}^{2}$ & Ссылка \\
\hline $\begin{array}{c}\mathrm{Al}-\mathrm{Cu}-\mathrm{Zr} \\
\quad \text { (Initial) }\end{array}$ & $617 \pm 78$ & $4.0503 \pm 0.0001$ & $362 \pm 7$ & $0.068 \pm 0.0009$ & 2.3 & \multirow{3}{*}{$\begin{array}{c}\text { [настоящая } \\
\text { статья] }\end{array}$} \\
\hline $\begin{array}{c}\mathrm{Al}-\mathrm{Cu}-\mathrm{Zr} \\
(\mathrm{AG})\end{array}$ & $630 \pm 90$ & $4.0497 \pm 0.0001$ & $588 \pm 13$ & $0.020 \pm 0.0003$ & 0.4 & \\
\hline $\begin{array}{c}\mathrm{Al}-\mathrm{Cu}-\mathrm{Zr} \\
\left(\mathrm{AG} \_\mathrm{HPT}\right)\end{array}$ & $285 \pm 23$ & $4.0504 \pm 0.0001$ & $205 \pm 1$ & $0.044 \pm 0.002$ & 2.6 & \\
\hline $\begin{array}{c}\mathrm{Al}-\mathrm{Mg}-\mathrm{Zr}- \\
\left(\mathrm{AG} \_\mathrm{HPT}\right)\end{array}$ & $400 \pm 12$ & $4.0527 \pm 0.0001$ & $304 \pm 15$ & $0.026 \pm 0.001$ & 1.0 & {$[14]$} \\
\hline $\begin{array}{c}\mathrm{Al}-\mathrm{Zr} \\
\left(\mathrm{AG} \_\mathrm{HPT}\right)\end{array}$ & $945 \pm 17$ & $4.0504 \pm 0.0001$ & $310 \pm 10$ & $0.006 \pm 0.002$ & 0.23 & {$[12]$} \\
\hline
\end{tabular}

свойств при повышенной температуре. Достаточно равномерно расположенные в зернах сферические частицы со средним размером $d_{p t} \approx 9.3 \mathrm{~nm}$ (рис. 3,c), узким распределением по размеру (рис. $3, d$ ) и концентрацией $n_{p t} \approx 4 \cdot 10^{21}$ подобны таковым, наблюдаемым в $\mathrm{Al}-\mathrm{Zr}$ сплавах $[4,11,26]$. Например, после длительного отжига при $375^{\circ} \mathrm{C}$ в сплаве $\mathrm{Al}-0.4 \mathrm{Zr}$ (wt.\%) наблюдались подобные распределения дисперсных преципитатов $\mathrm{Al}_{3} \mathrm{Zr}$ (фаза $\mathrm{L1}_{2}$ ) со средним размером $13 \mathrm{~nm}$ и концентрацией $n_{p t} \approx 3.63 \cdot 10^{21}$ [11], а в сплаве $\mathrm{Al}-0.53 \mathrm{Mg}-0.27 \mathrm{Zr}(\mathrm{wt} . \%)$ наблюдались подобные частицы с $d_{p t} \approx 15 \mathrm{~nm}$ [14].

По границам зерен располагаются более крупные частицы со средним размером $\sim 34 \mathrm{~nm}$. Принадлежность их фазе $\mathrm{Al}_{3} \mathrm{Zr}$ была дополнительно подтверждена анализом ЭДС (рис. 4). Формирование на ГЗ более крупных частиц связано с тем, что на границах диффузионные процессы проходят более активно, так как коэффициент зернограничной диффузии значительно превышает коэффициент объемной диффузии [27].

После обработки ИПДК микроструктура сплава становится ультрамелкозернистой (рис. 5). Средний размер зерна составил $285 \mathrm{~nm}$, что значительно меньше размера зерна $D_{a v}^{G}=945 \mathrm{~nm}$ в подобном сплаве $\mathrm{Al}-0.4 \mathrm{Zr}$ _AG_HPT без добавления меди, и меньше по сравнению со сплавом $\mathrm{Al}-0.53 \mathrm{Mg}-0.27 \mathrm{Zr} \_\mathrm{AG} \_\mathrm{HPT}$ $\left(D_{a v}^{G}=400 \mathrm{~nm}\right)$, легированным магнием в сравнимых атомных концентрациях (табл. 2). Полученные данные показывают, что легирование медью более эффективно для измельчения зерна, чем легирование $\mathrm{Mg}$ в сравнимых концентрациях в системах $\mathrm{Al}-(\mathrm{Mg} / \mathrm{Cu})-\mathrm{Zr}$.

Количество частиц фазы $\mathrm{Al}_{3} \mathrm{Zr}$ после обработки ИПДК значительно уменьшилось, что свидетельствует о том, что большая их часть растворилась в матрице твердого раствора под действием ИПДК, т. е. произошло деформационно-индуцированное растворение вторичных фаз. Типичные ЭДС-карты образцов в состояниях AG и AG_HPT представлены соответственно на рис. 6 и 7,

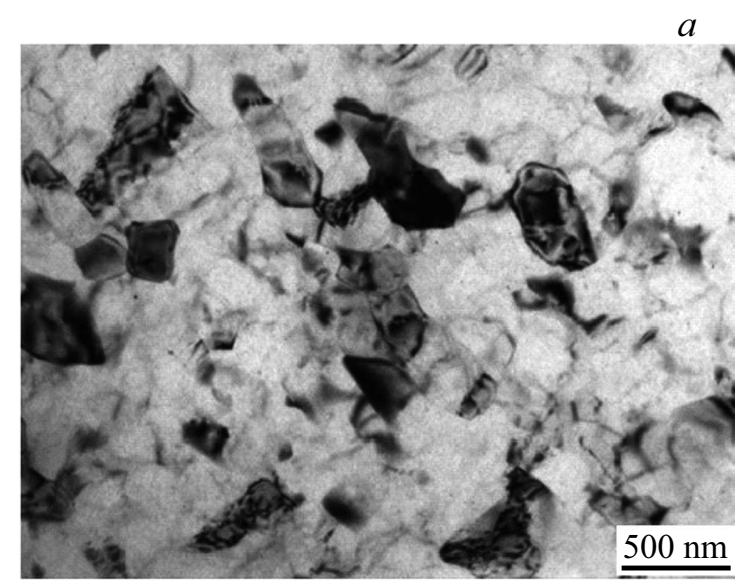

$a$

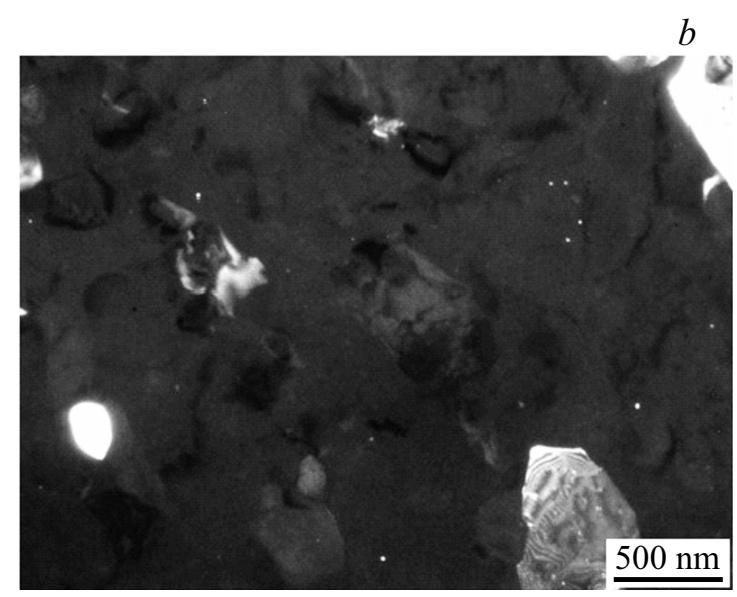

Рис. 5. ПЭМ-изображения микроструктуры сплава $\mathrm{Al}-\mathrm{Cu}-\mathrm{Zr}$ в состоянии AG_HPT в светлопольном $(a)$ и в темнопольном $(b)$ режимах.

которые подтверждают значительное увеличение концентрации $\mathrm{Zr}$ в алюминиевой матрице после обработки ИПДК. Аналогичное явление наблюдалось для сплавов $\mathrm{Al}-0.4 \mathrm{Zr}$ [11], $\mathrm{Al}-\mathrm{Mg}-\mathrm{Zr}$ [14] в результате обработки 
$a$
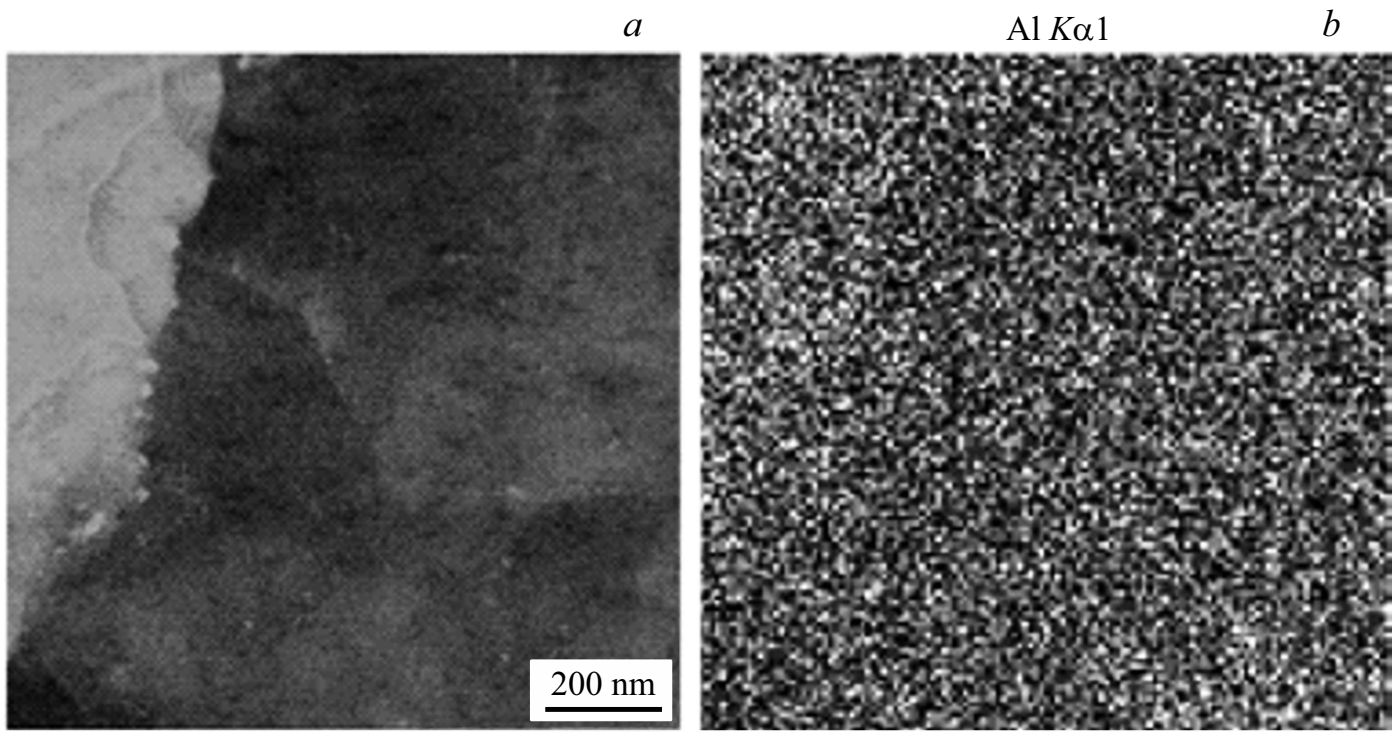

$\mathrm{Cu} K \alpha 1$

$\operatorname{Zr} L \alpha 1$

$d$
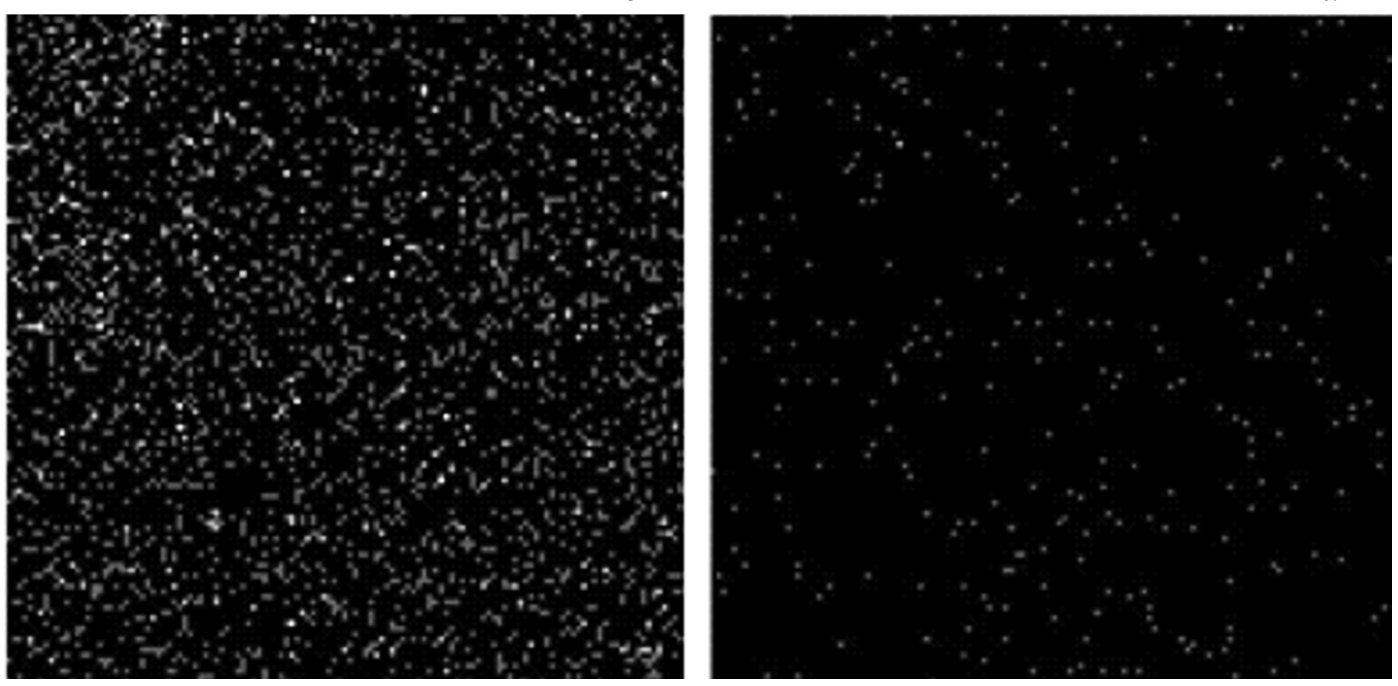

Рис. 6. ПРЭМ-изображение сплава $\mathrm{Al}-\mathrm{Cu}-\mathrm{Zr}$ в состоянии $\mathrm{AG}(a)$ и соответствующие ЭДС-карты распределений $\mathrm{Al}(b), \mathrm{Cu}(c)$ и $\mathrm{Zr}(d)$.

ИПДК. Воздействие ИПДК на предварительно состаренные сплавы $\mathrm{Al}-0.4 \mathrm{Zr}$ [11] и $\mathrm{Al}-\mathrm{Mg}-\mathrm{Zr}$ [14] приводило к частичному растворению фазы $\mathrm{Al}_{3} \mathrm{Zr}\left(\mathrm{L}_{2}\right)$. В случае $\mathrm{Al}-\mathrm{Mg}-\mathrm{Zr}$ [14] увеличение концентрации $\mathrm{Zr}$ в матрице $\mathrm{Al}$ в результате ИПДК было подтверждено атомной пространственной томографией. $\mathrm{B}$ сплаве $\mathrm{Al}-0.4 \mathrm{Zr}$ частичное растворение сопровождалось увеличением размеров оставшихся частиц $\mathrm{Al}_{3} \mathrm{Zr}$ [11]. Как видно из рис. 5, в образцах Al-Cu-Zr_AG_HPT частиц вторичной фазы $\mathrm{Al}_{3} \mathrm{Zr}$ значительно меньше по сравнению с образцами $\mathrm{Al}-\mathrm{Cu}-\mathrm{Zr} \_\mathrm{AG}$, располагаются они преимущественно в объеме зерен и их средний размер составил $d_{p t} \approx 17 \mathrm{~nm}$. Принадлежность таких частиц фазе $\mathrm{Al}_{3} \mathrm{Zr}$ была подтверждена ЭДС-анализом. Кроме того, после обработки ИПДК на ГЗ наблюдались отдельные $\mathrm{Cu}$-содержащие частицы с размерами 20-40 nm (рис. 8). Принадлежность этих частиц медным фазам была подтверждена ЭДС- анализом (рис. 8,c). Такие частицы, по-видимому, принадлежат преимущественно $\theta$-фазе, поскольку, согласно [17], переход $\theta^{\prime}-\theta$ происходит при достижении сферическими частицами критического размера $\sim 23 \mathrm{~nm}$. ЭДС-сканирование показало, что оставшиеся атомы $\mathrm{Cu}$ и $\mathrm{Zr}$ распределялись по зернам достаточно равномерно (рис. 7, $c, d$ ).

Данные микроструктурного анализа для состояний $\mathrm{Al}-\mathrm{Cu}-\mathrm{Zr}$ _AG и $\mathrm{Al}-\mathrm{Cu}-\mathrm{Zr} \_\mathrm{AG}-\mathrm{HPT}$, полученные методами ПЭМ и РСА, приведены в табл. 2. Там же для сравнения показаны микроструктурные параметры для сплавов $\mathrm{Al}-0.4 \mathrm{Zr}$ (wt.\%) и $\mathrm{Al}-0.53 \mathrm{Mg}-0.27 \mathrm{Zr}$ (wt.\%) в подобном состоянии.

Согласно данным рентгеноструктурного анализа, для сплава $\mathrm{Al}-\mathrm{Cu}-\mathrm{Zr}$ параметр решетки $а$ незначительно отличается во всех трех состояниях, что свидетельствует о том, что в этих состояниях концентрация $\mathrm{Cu}$ в твердом 

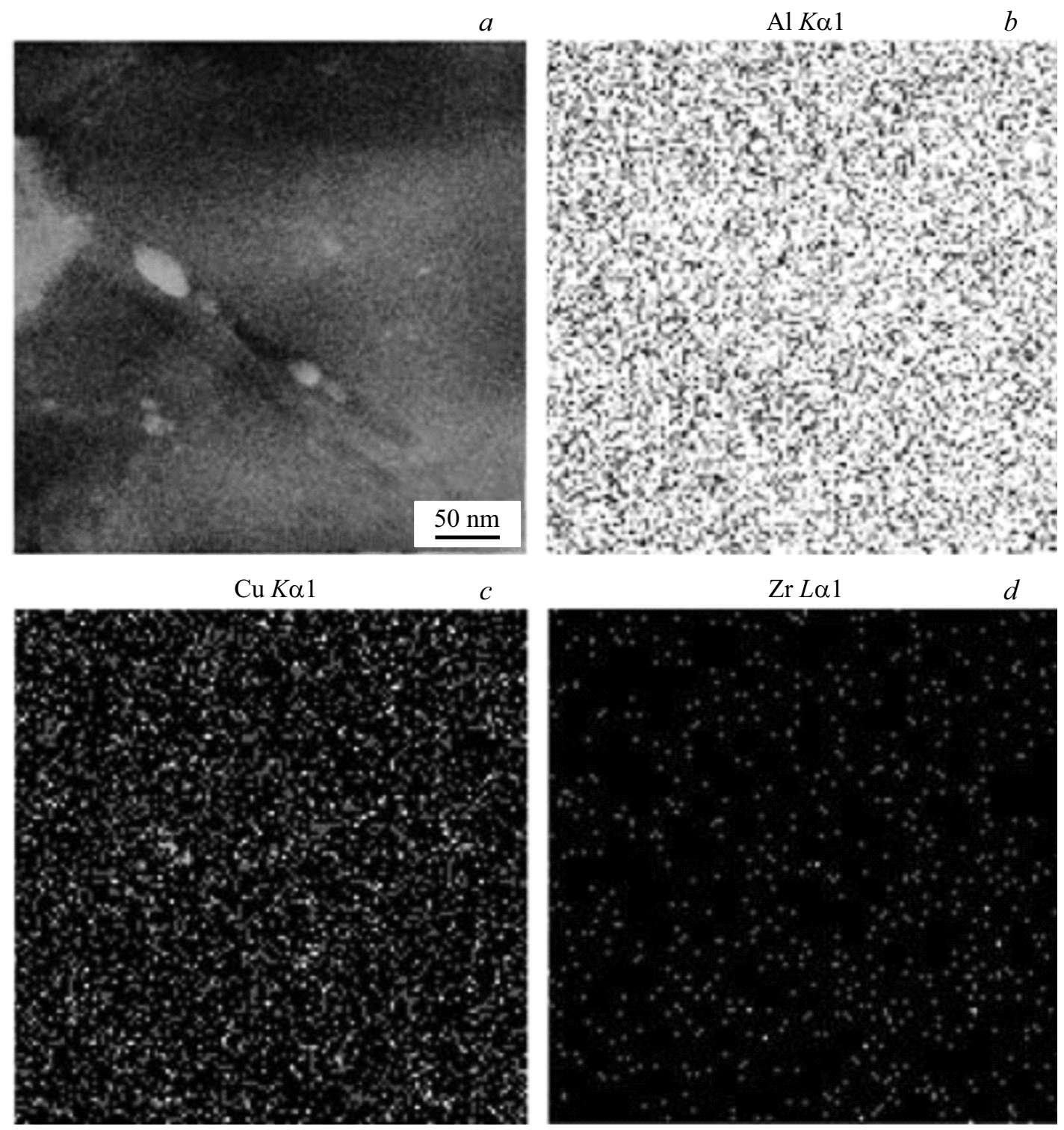

Рис. 7. ПРЭМ-изображение сплава $\mathrm{Al}-\mathrm{Cu}-\mathrm{Zr}$ в состоянии $\mathrm{AG} \_\mathrm{HPT}(a)$ и соответствующие ЭДС-карты распределений $\mathrm{Al}(b)$, $\mathrm{Cu}(c)$ и $\mathrm{Zr}(d)$.

растворе значительно не различается. Известно, что наличие атомов Zr в малых концентрациях в матрице алюминия не влияет на параметр решетки [14]. Плотность дислокаций в образцах $\mathrm{Al}-\mathrm{Cu}-\mathrm{Zr} \_\mathrm{AG} \_\mathrm{HPT}$ на порядок выше плотности дислокаций в подобных образцах без добавки $\mathrm{Cu}\left(\mathrm{Al}-0.4 \mathrm{Zr} \_\mathrm{AG} \_\mathrm{HPT}\right)$ и в 2.6 раза выше, чем в образцах, легированных $\mathrm{Mg}\left(\mathrm{Al}-\mathrm{Mg}-\mathrm{Zr} \_\mathrm{AG} \_\mathrm{HPT}\right)$.

\section{2. Механические свойства и электропроводность}

На рис. 9 представлены диаграммы напряжениедеформация для образцов сплава $\mathrm{Al}-\mathrm{Cu}-\mathrm{Zr}$ в состояниях $\mathrm{Al}-\mathrm{Cu}-\mathrm{Zr} \_I n i t i a l, \mathrm{Al}-\mathrm{Cu}-\mathrm{Zr} \_\mathrm{AG}$ и $\mathrm{Al}-\mathrm{Cu}-$ $\mathrm{Zr} \_\mathrm{AG} \_\mathrm{HPT}$. Значения основных механических характеристик, таких как условный предел текучести $\sigma_{0.2}$, предел прочности $\sigma_{U T S}$ и пластичность $\delta$, определенные из анализа полученных деформационных кривых, а также значения микротвердости $H_{V}$ и электропроводности $\omega$ представлены в табл. 3. В табл. 3 для сравнения аналогичных характеристик также представлены данные для сплавов $\mathrm{Al}-\mathrm{Mg}-\mathrm{Zr}$ и $\mathrm{Al}-\mathrm{Zr}$.

ИПДК-структурирование привело к значительному повышению прочности: $H_{V}$ увеличилась в 2.6 раза, $\sigma_{U T S}$ в 2.7 раза, $\sigma_{0.2}$ в 2.5 раза. Однако $\delta$ уменьшилась значительно: с $17 \%$ до $5 \%$. Следует отметить, что легирование $1.47 \mathrm{wt} . \% \mathrm{Cu}$ (соответствует 0.63 at.\%) обеспечило большее увеличение прочности по сравнению с легированием 0.6 at.\% $\mathrm{Mg}$ в системе $\mathrm{Al}-\mathrm{Cu}(\mathrm{Mg})-\mathrm{Zr}$ с приблизительно одинаковой концентрацией $\mathrm{Zr}$ (табл. 3), особенно это касается предела прочности: $~ 575 \mathrm{MPa} \mathrm{в}$ 

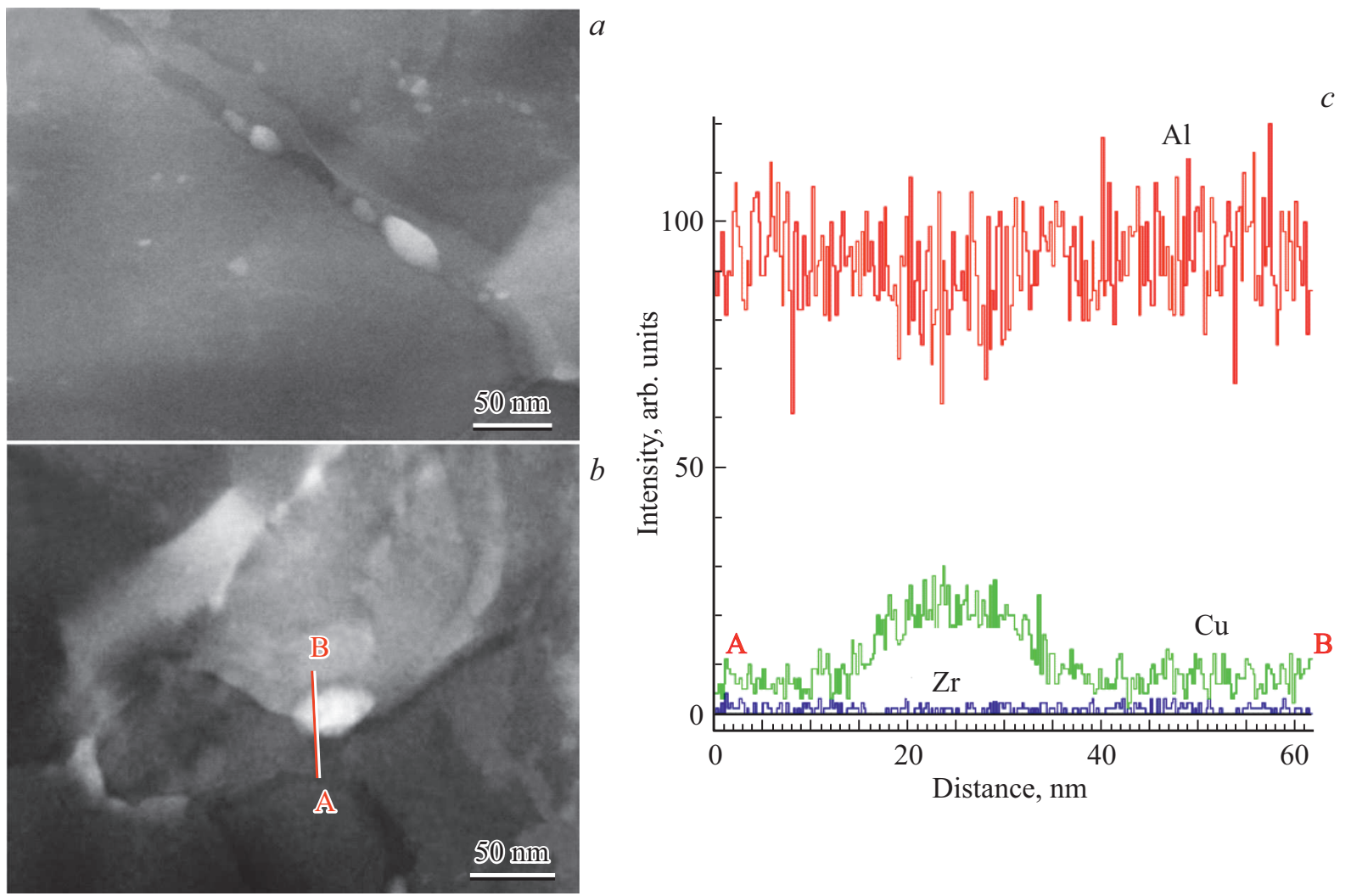

Рис. 8. ПРЭМ-изображения $(a, b)$ и ЭДС-анализ $(c)$ вдоль линии $\mathrm{AB}$, обозначенной на $(b)$, для сплава $\mathrm{Al}-\mathrm{Cu}-\mathrm{Zr}$ в состоянии AG_HPT.

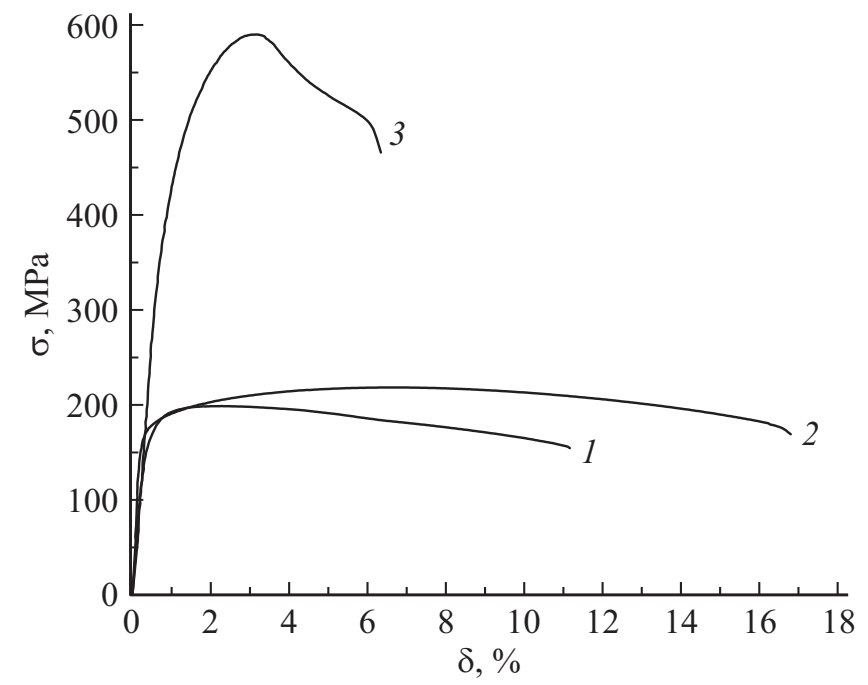

Рис. 9. Диаграммы напряжение-деформация образцов сплава $\mathrm{Al}-\mathrm{Cu}-\mathrm{Zr}$ в различных состояниях: $1-$ Initial, $2-\mathrm{AG}, 3-$ AG_HPT.

$\mathrm{Al}-\mathrm{Cu}-\mathrm{Zr} \_\mathrm{AG} \_\mathrm{HPT}$ (настоящая работа) по сравнению $\mathrm{c} \sim 465 \mathrm{MPa}$ в Al-Mg-Zr_AG_HPT [14].

Исходя из данных, представленных выше, и их сравнения с механическими свойствами сплавов $\mathrm{Al}-0.4 \mathrm{Zr}$ (wt.\%) [11] и $\mathrm{Al}-\mathrm{Mg}-\mathrm{Zr}$ [14] (табл. 3), также прошедших предварительное старение (длительный отжиг для формирования дисперсных вторичных фаз) и последующую обработку ИПДК, можно сделать вывод, что основная роль в упрочнении исследуемого сплава $\mathrm{Al}-\mathrm{Cu}-\mathrm{Zr} \_\mathrm{AG} \_\mathrm{HPT}$ принадлежит $\mathrm{Cu}$.

\section{4. Обсуждение результатов}

Известно, что электропроводность металлов наиболее чувствительна к легирующим элементам, находящимся в твердом растворе. В исходном состоянии образцы $\mathrm{Al}-\mathrm{Cu}-\mathrm{Zr}$ _Initial демонстрируют низкий уровень электропроводности, что свидетельствует о том, что легирующие элементы находятся в матрице $\mathrm{Al}$ в твердом растворе. После длительного отжига электропроводность значительно возросла и составила $54.8 \%$ IACS для состояния $\mathrm{Al}-\mathrm{Cu}-\mathrm{Zr} \_\mathrm{AG}$. Это связано, в первую очередь, с очищением матрицы от твердого раствора в результате выпадения вторичных фаз, что хорошо согласуется с данными микроструктурных исследований (рис. 3, $a, b, c)$.

Обработка ИПДК привела к значительному уменьшению электропроводности - на $\sim 8.7$ \% IACS (или увеличению удельного электросопротивления на $\Delta \rho \approx 5.9 \mathrm{n} \Omega \mathrm{m}$ ) (табл. 3). Это связано, главным образом, 
Таблица 3. Механические и электрические свойства сплавов

\begin{tabular}{|c|c|c|c|c|c|c|c|c|c|}
\hline Материал & Состояние & $H_{V}, \mathrm{MPa}$ & $\sigma_{0.2}, \mathrm{MPa}$ & $\sigma_{U T S}, \mathrm{MPa}$ & $\delta, \%$ & $\omega, \mathrm{MS} / \mathrm{m}$ & $\omega, \%$ IACS & $\rho, \mathrm{n} \Omega \mathrm{m}$ & Ссылка \\
\hline \multirow{3}{*}{$\mathrm{Al}-\mathrm{Cu}-\mathrm{Zr}$} & Initial & $650 \pm 45$ & $180 \pm 10$ & $200 \pm 1$ & $10.5 \pm 0.8$ & $19.6 \pm 0.36$ & $33.7 \pm 0.6$ & 51.0 & \multirow{3}{*}{$\begin{array}{c}\text { [Настоящая } \\
\text { работа] }\end{array}$} \\
\hline & $\mathrm{AG}$ & $640 \pm 15$ & $170 \pm 15$ & $215 \pm 5$ & $17.0 \pm 1.3$ & $31.85 \pm 0.06$ & $54.8 \pm 0.1$ & 31.4 & \\
\hline & AG_HPT & $1640 \pm 35$ & $430 \pm 15$ & $575 \pm 10$ & $4.9 \pm 1.8$ & $26.8 \pm 0.1$ & $46.1 \pm 0.2$ & 37.3 & \\
\hline \multirow{2}{*}{$\mathrm{Al}-\mathrm{Mg}-\mathrm{Zr}$} & $\mathrm{AG}$ & $555 \pm 40$ & $117 \pm 6$ & $155 \pm 3$ & $20.3 \pm 2.0$ & $32.25 \pm 0.10$ & $55.6 \pm 0.2$ & 31.0 & \multirow{2}{*}[14]{} \\
\hline & AG_HPT & $1240 \pm 20$ & $400 \pm 10$ & $465 \pm 10$ & $3-5$ & $30.00 \pm 0.15$ & $51.5 \pm 0.3$ & 33.3 & \\
\hline \multirow{2}{*}{$\mathrm{Al}-0.4 \mathrm{Zr}$} & $\mathrm{AG}$ & $399 \pm 22$ & $72 \pm 6$ & $95 \pm 4$ & $27 \pm 2$ & 34.1 & 58.8 & 29.3 & \multirow{2}{*}[11]{} \\
\hline & AG_HPT & $464 \pm 3$ & $96 \pm 2$ & $118 \pm 2$ & $28.0 \pm 0.6$ & 32.4 & 55.8 & 30.8 & \\
\hline
\end{tabular}

с частичным растворением частиц вторичной фазы $\mathrm{Al}_{3} \mathrm{Zr}$ и переходом $\mathrm{Zr}$ в твердый раствор в процессе ИПДК, а также с уменьшением размера зерна (увеличением плотности границ зерен) и значительным увеличением плотности дислокаций $L_{d i s}$ (табл. 2). Результаты по изменению электросопротивления находятся в хорошем согласии с данными микроструктурных исследований (раздел 3.1). С другой стороны, формирование $\mathrm{Cu}$-содержащих частиц приводит к уменьшению концентрации $\mathrm{Cu}$ в твердом растворе и, следовательно, способствует уменьшению электросопротивления. Одноко, судя по тому, что ЭДС-карты атомов $\mathrm{Cu}$ сравнимы по концентрации (рис. 6,7), общая объемная доля $\mathrm{Cu}$-содержащих частиц невелика. Следовательно, формирование таких частиц не может значительно повлиять на величину электросопротивления.

Изменение электросопротивления из-за изменения плотности границ зерен после обработки ИПДК можно оценить как [28]:

$$
\Delta \rho_{G B}=\Delta S_{G B} \delta \rho^{G B},
$$

где $\Delta S_{G B}$ - изменение объемной плотности границ зерен после ИДПК, $\delta \rho^{G B}=2.6 \cdot 10^{-16} \Omega \mathrm{m}^{2}-$ вклад в электросопротивление от единичной плотности границ зерен. Величина $\Delta \rho_{G B}$ составляет $\sim 0.7 \mathrm{n} \Omega \mathrm{m}$.

Вклад от увеличения плотности дислокаций, определенный в соответствии с формулой [29],

$$
\Delta \rho_{d i s}=L_{d i s} \delta \rho^{d i s} \text {, }
$$

где $\delta \rho^{d i s}=2.7 \cdot 10^{-25} \mathrm{~m} \Omega \mathrm{m}^{3}-$ вклад в электросопротивление от единичной плотности дислокаций. Полученное значение $\Delta \rho_{\text {dis }} \approx 7 \cdot 10^{-3} \mathrm{n} \Omega \mathrm{m}$ пренебрежимо мало. Следует также отметить, что вклад вакансий в электрическое сопротивление в УМЗ алюминиевых сплавах, структурированных разными методами ИПД, также пренебрежимо мал $[28,30]$.

Согласно $[11,14]$, после аналогичной термомеханической обработки (AG_HPT) 50\% атомов $\mathrm{Zr}$ переходит в твердый раствор для сплавов $\mathrm{Al}-0.4 \mathrm{Zr}$ [11] и $\mathrm{Al}-\mathrm{Mg}-\mathrm{Zr}$ [14]. Исходя из подобной доли атомов $\mathrm{Zr}$ в твердом растворе и для сплава $\mathrm{Al}-\mathrm{Cu}-\mathrm{Zr} \_\mathrm{AG} \_\mathrm{HPT}$, можно оценить вклад в электросопротивление от атомов $\mathrm{Zr}$, перешедших в твердый раствор как [14]:

$$
\Delta \rho_{S S}^{\mathrm{Zr}}=\delta \rho_{S S}^{\mathrm{Zr}} \Delta \mathrm{C}_{\mathrm{Zr}}^{S S},
$$

где $\delta \rho_{S S}^{\mathrm{Zr}}=15.8 \mathrm{n} \Omega \mathrm{m} / \mathrm{wt} . \%$ [31] - вклад в электропроводность единичной концентрации $\mathrm{Zr}$ в твердом растворе, $\Delta \mathrm{C}_{\mathrm{Zr}}^{S S}$ - изменение концентрации $\mathrm{Zr}$ в твердом растворе в процессе ИПДК. Величина $\Delta \rho_{S S}^{\mathrm{Zr}} \approx 2.7 \mathrm{n} \Omega \mathrm{m}$. Следовательно, оставшаяся разница $\Delta \rho_{a d} \sim 2.5 \mathrm{n} \Omega \mathrm{m}$ в электросопротивлении сплава в состояниях AG и AG_HPT вызвана действием некоторых дополнительных механизмов рассеяния электронов проводимости после обработки ИПДК. Повышению электросопротивления в образцах после обработки ИПДК может способствовать формирование сегрегаций примесных элементов на ГЗ. Образование частиц $\mathrm{Cu}$-содержащей вторичной фазы на ГЗ в состоянии AG_HPT может сопровождаться формированием сегрегаций $\mathrm{Cu}$ на ГЗ, как это наблюдалось в сплаве $\mathrm{Al}-\mathrm{Cu}$ со сравнимой концентрацией $\mathrm{Cu}(0.83$ at.\%) [18]. Не исключено также образование ультрамелких кластеров меди как на ГЗ, так и в теле зерна, которые слишком малы для обнаружения методами электронной микроскопии и которые могут тоже приводить к дополнительному рассеянию заряда. На возможность формирования ультрамелких нанокластеров атомами легирующих элементов, в том числе $\mathrm{Cu}$, в алюминиевых сплавах указывалось ранее в работах [32,33].

На базе полученных микроструктурных параметров мы можем оценить вклады в общее упрочнение от известных для крупнозернистого состояния механизмов упрочнения. Обычно общее упрочнение металлов и сплавов является суммой вкладов различных механизмов в общее упрочнение [34] :

$$
\sigma_{0.2}^{t h}=\sigma_{0}+\sigma_{s s}+\sigma_{d i s}+\sigma_{G B}+\sigma_{p t},
$$

где $\sigma_{0}=10 \mathrm{MPa}$ - напряжение Пайерлса-Набарро кристаллической решетки $\mathrm{Al}[35], \sigma_{G B}$ - зернограничное упрочнение, $\sigma_{d i s}$ - дислокационное упрочнение, $\sigma_{p t}-$ упрочнение частицами вторичной фазы и $\sigma_{s s}$ - твердорастворное упрочнение. 
Зернограничное упрочнение определяется соотношением Холла-Петча [36]:

$$
\sigma_{G B}=K D_{a v}^{-1 / 2},
$$

где $\quad K=0.07 \mathrm{MPa} \cdot \mathrm{m}^{1 / 2}-$ коэффициент $\quad$ ХоллаПетча [37], $D_{a v}-$ средний размер зерна. Аналогично работам $[12,14,38]$, для оценки зернограничного упрочнения значение коэффициента было взято равным $K=0.07 \mathrm{MPa} \cdot \mathrm{m}^{1 / 2}$. Следует отметить, что для такого значения коэффициента $K$ теоретические оценки вкладов (не показанных здесь) в упрочнение и полученное, соответственно, теоретическое значение предела текучести для исходного состояния находятся в хорошем количественном согласии с экспериментальным значением $\sigma_{0.2}$.

Вклад от дислокационного упрочнения можно оценить по формуле Тэйлора [39]:

$$
\sigma_{d i s}=M \alpha G b L_{d i s}^{1 / 2},
$$

где $M=3.06$ - фактор Тейлора [39], $\alpha=0.33$ параметр междислокационного взаимодействия [40], $G=26 \mathrm{GPa}-$ модуль сдвига, $b=0.286 \mathrm{~nm}-$ величина вектора Бюргерса, $L_{d i s}$ - плотность дислокаций.

Вклад от примесных элементов, находящихся в твердом растворе, можно определить как [41]:

$$
\sigma_{S S}=\sum k_{i}\left(C_{i}^{S S}\right)^{2 / 3},
$$

где для циркония $k_{\mathrm{Zr}}=9 \mathrm{MPa}(\text { wt.\% })^{-2 / 3}[11]$, для меди $k_{\mathrm{Cu}}=46.4 \mathrm{MPa}(\text { wt.\% })^{-2 / 3}[41]$.

Максимально возможное твердорастворное упрочнение достигается при условии нахождения всех примесей легирующих элементов в твердом растворе, в этом случае $\sigma_{s s} \approx 64.4 \mathrm{MPa}$. Для состояния $\mathrm{Al}-\mathrm{Cu}-\mathrm{Zr} \_\mathrm{AG} \_\mathrm{HPT}$ такое значение является завышенным, так как, согласно микроструктурным данным и данным по изменению электросопротивления, часть легирующих элементов находится в преципитатах вторичной фазы.

Вклад в упрочнение от наноразмерных частиц фазы $\mathrm{Al}_{3} \mathrm{Zr}$ можно оценить из упрочнения по механизму Орована, так как размер частиц превышает критическое значение $d_{p t} \approx 5.6 \mathrm{~nm}$, ниже которого реализуется механизм упрочнения за счет перерезания частиц $[42,43]$. Согласно $[42,43]$, упрочнение по механизму Орована можно оценить как

$$
\sigma_{\mathrm{Or}}=\frac{0.4 M G_{\mathrm{Al}} b}{\pi L} \cdot \frac{\ln (\pi\langle r\rangle / 2 b)}{\sqrt{1-v}},
$$

где $G_{\mathrm{Al}}=26 \mathrm{GPa}$ - модуль сдвига, $v=0.345-$ коэффициент Пуассона [44], $\langle r\rangle-$ средний радиус частиц, $L-$ расстояние между преципитатами, которое можно оценить по формуле [43]:

$$
L=\langle r\rangle\left(\sqrt{\frac{2 \pi}{3 f_{V}}}-\frac{\pi}{2}\right),
$$

где $f_{V}$ - общая объемная доля частиц фазы $\mathrm{Al}_{3} \mathrm{Zr}$.
Согласно работам [11] и [14], в аналогичных предварительно состаренных сплавах $\mathrm{Al}-0.4 \mathrm{Zr} \quad[11]$ и $\mathrm{Al}-0.53 \mathrm{Mg}-0.27 \mathrm{Zr}$ [14] при обработке ИПДК большая доля $\mathrm{Zr}$ переходит в твердый раствор, а на преципитаты $\mathrm{Al}_{3} \mathrm{Zr}$ остается $0.22-0.24 \mathrm{vol} . \%$. Исходя из этой объемной доли, оценка вклада в упрочнение от преципитатов $\mathrm{Al}_{3} \mathrm{Zr}$ размером $d_{p t}=17 \mathrm{~nm}$ в состоянии $\mathrm{Al}-\mathrm{Cu}-\mathrm{Zr} \_\mathrm{AG} \_\mathrm{HPT}$ дает значение $\sigma_{p t}=55-57.5 \mathrm{MPa}$. Полученные оценки вкладов в упрочнение и общего суммарного упрочнения $\sigma_{0.2}^{\text {th }}$ приведены в табл. 4. Видно, что экспериментально полученное значение $\sigma_{0.2}^{e x p}=430 \mathrm{MPa}$ значительно превышает $\sigma_{0.2}^{\text {th }} \approx 300 \mathrm{MPa}$. Таким образом, на упрочнение от легирования медью дополнительно к вкладу в твердорастворное упрочнение $(<60 \mathrm{MPa})$ приходится еще не менее $130 \mathrm{MPa}$.

Это означает, что помимо вклада меди в твердорастворное упрочнение за счет нахождения доли ее в твердом растворе и в зернограничное упрочнение за счет уменьшения размера зерна (плотности границ зерен) в состоянии $\mathrm{Al}-\mathrm{Cu}-\mathrm{Zr} \_\mathrm{AG} \_\mathrm{HPT}$, присутствие меди вызывает колоссальное дополнительное упрочнение, нетипичное для крупнозернистого состояния.

Наиболее вероятной причиной такого дополнительного упрочнения сплава $\mathrm{Al}-\mathrm{Cu}-\mathrm{Zr} \_\mathrm{AG} \_\mathrm{HPT}$ может быть сегрегация $\mathrm{Cu}$ в границах зерен. Известно, что медь активно сегрегирует в ГЗ в процессе ИПДК-обработки сплавов системы $\mathrm{Al}-\mathrm{Cu}$, в которых исходно $\mathrm{Cu}$ находилась в состоянии твердого раствора $[18,45]$. Сегрегация $\mathrm{Cu}$ в ГЗ наблюдалась в сплаве системы $\mathrm{Al}-\mathrm{Zn}-\mathrm{Mg}-\mathrm{Cu}$ (с содержанием меди $2.5 \mathrm{wt} . \%$ ), подвергнутого равноканальному угловому прессованию при $200^{\circ} \mathrm{C}$ [45]. В работе [18] исследовался сплав $\mathrm{Al}-0.83$ at.\% $\mathrm{Cu}$ (с близкой нашему случаю концентрацией $\mathrm{Cu}$ ), подвергнутый обработке ИПДК при комнатной температуре, и было показано, что начиная уже с ранних стадий деформации (0.5 оборота) происходит распад твердого раствора и сегрегация $\mathrm{Cu}$ в границы зерен с увеличением ее концентрации на ГЗ в 3-4 раза по сравнению с концентрацией в зерне и шириной концентрационного профиля $\sim 1-2 \mathrm{~nm}$. С увеличением степени ИПДК происходит формирование наноразмерных частиц преимущественно $\theta$-фазы на ГЗ. В нашем случае обработка ИПДК применяется к предварительно состаренному сплаву, в котором уже имеются выделения фазы $\mathrm{Al}_{3} \mathrm{Zr}$. Наши микроструктурные исследования и данные по изменению электросопротивления показали, что происходит частичное растворение этой фазы в результате ИПДК. Поскольку в процессе ИПДК образуется много дефектов (вакансий, дислокаций, новых ГЗ), которые ускоряют диффузионные процессы, то растворение также может сопровождаться сегрегационными процессами примесных элементов. Формирование Сu-содержащих частиц на ГЗ (рис. 8) в результате ИПДК косвенно указывает на такие сегрегационные процессы.

Согласно [46,47] начало пластического течения в УМ3 Al с размером зерна $<1000 \mathrm{~nm}$ контролируется эмиссией дислокаций из границ зерен, при этом границы 
Таблица 4. Оценки вкладов различных механизмов упрочнения в прочность различных алюминиевых сплавов в состояниях AG_HPT в сравнении с экспериментальным значением предела текучести

\begin{tabular}{|c|c|c|c|c|c|c|c|c|}
\hline $\begin{array}{c}\text { Материал } \\
\text { и его состояние }\end{array}$ & $\sigma_{0}, \mathrm{MPa}$ & $\sigma_{G B}, \mathrm{MPa}$ & $\sigma_{d i s}, \mathrm{MPa}$ & $\sigma_{S S}, \mathrm{MPa}$ & $\sigma_{\mathrm{Or}}, \mathrm{MPa}$ & $\sigma_{0.2}^{t h}, \mathrm{MPa}$ & $\sigma_{0.2}^{\exp }, \mathrm{MPa}$ & Ссылка \\
\hline $\begin{array}{c}\mathrm{Al}-1.47 \mathrm{Cu}-0.34 \mathrm{Zr} \\
\left(\mathrm{AG} \_\mathrm{HPT}\right)\end{array}$ & 10.0 & 131.0 & 38.3 & $<64.4$ & $55.0-57.5$ & $299-301$ & 430 & $\begin{array}{c}\text { Настоящая } \\
\text { работа }\end{array}$ \\
\hline $\begin{array}{c}\mathrm{Al}-0.53 \mathrm{Mg}-0.27 \mathrm{Zr} \\
\left(\mathrm{AG} \_\mathrm{HPT}\right)\end{array}$ & 10.0 & 110.7 & 24.2 & $<22.8$ & $80-84$ & $249-253$ & 400 & {$[14]$} \\
\hline $\begin{array}{l}\mathrm{Al}-0.4 \mathrm{Zr} \\
\left(\mathrm{AG} \_\mathrm{HPT}\right)\end{array}$ & 10.0 & 77.0 & 11.3 & 4.4 & - & 97.8 & 96 & {$[12]$} \\
\hline
\end{tabular}

зерен могут служить как источниками, так и стоками для дислокаций [48]. В УМЗ-структуре дислокации после эмиссии из границ будут перемещаться через зерно и захватываться противоположными границами зерен с последующим переползанием по границе и частичной аннигиляцией, обеспечивая динамический возврат дислокационной структуры. Сегрегация примесных элементов на ГЗ может влиять на критическое напряжение испускания дислокаций.

Например, в [49] методом АПТ была обнаружена значительная сегрегация $\mathrm{Mg}$ по границам зерен в УМЗ сплаве $\mathrm{Al}$ с $5.7 \mathrm{wt} \% \mathrm{Mg}$, структурированном методом ИПДК, и было высказано предложение, что именно такая сегрегация приводит к значительному увеличению прочности этого УМЗ сплава за счет препятствования эмиссии дислокаций из ГЗ. Кроме того, в течение деформации ГЗ могут действовать как барьеры для скольжения дислокаций, вызывая скопление дислокаций перед ГЗ. Только при достижении некоторого критического напряжения скольжение будет инициироваться в соседнем зерне. Сегрегации могут увеличивать это критическое напряжение и, следовательно, увеличивать коэффициент $K$ в уравнении Холла-Петча (7) [50,51]. Теоретические расчеты из первых принципов [51] и методами молекулярной динамики [52] также показали, что сегрегация $\mathrm{Cu}$ и $\mathrm{Mg}$ в ГЗ приводит к увеличению предела текучести в УМЗ Аl.

Примечательно, что подобное дополнительное упрочнение $(\sim 150 \mathrm{MPa})$ было выявлено и в сплаве $\mathrm{Al}-\mathrm{Mg}-\mathrm{Zr}$ _AG_HPT co сравнимой концентрацией $\mathrm{Mg}$ - 0.6 at.\% (таблица 4 и [14]). Известно, что $\mathrm{Mg}$ тоже активно сегрегирует в ГЗ при обработке ИПДК $[53,54]$. Сегрегация $\mathrm{Cu}$ в ГЗ способствует некоторому очищению зерен от $\mathrm{Cu}$. Оценки показывают, что сегрегация, подобная наблюдаемой в работе [18], в нашем сплаве $\mathrm{Al}-\mathrm{Cu}-\mathrm{Zr}$ с номинальным содержанием меди $1.47 \mathrm{wt} . \%$ $(0.63$ at.\%) и размером зерна $\sim 300 \mathrm{~nm}$ привела бы лишь к незначительному уменьшению концентрации $\mathrm{Cu}$ в зерне (только на $\sim 0.02 \mathrm{wt} . \%$ ).

В случае формирования ультрамалых кластеров $\mathrm{Cu}$ в УМ3 сплаве $\mathrm{Al}-\mathrm{Cu}-\mathrm{Zr} \_\mathrm{AG} \_\mathrm{HPT}$, они также будут вносить вклад в упрочнение, однако их вклад, согласно оценке, проведенной в [33] для УМЗ-сплава $\mathrm{Al}-\mathrm{Zn}-\mathrm{Mg}-\mathrm{Cu}$ с близким содержанием $1.38 \mathrm{wt} . \% \mathrm{Cu}$, будет менее $44 \mathrm{MPa}$.

Таким образом, сопоставление экспериментальных значений прочности (предела текучести) и значений, рассчитанных на базе микроструктурных параметров и изменения электропроводности, указывает на действие дополнительных механизмов упрочнения в УМЗ структуре сплава системы $\mathrm{Al}-\mathrm{Cu}-\mathrm{Zr}$, структурированного методом ИПДК. Наиболее вероятными причинами такого значительного ( 130 MРa) упрочнения могут являться сегрегация $\mathrm{Cu}$ в границах зерен и формирование ультрамалых нанокластеров $\mathrm{Cu}$. Для прямого подтверждения указанных причин требуется продолжение исследований тонкой структуры ГЗ и атомного распределения $\mathrm{Cu}$ в пределах зерен методами атомной пространственной томографии.

\section{5. Заключение}

Впервые исследовано влияние ИПДК на микроструктуру, механические и электрические свойства предварительно состаренного сплава $\mathrm{Al}-1.47 \mathrm{Cu}-0.34 \mathrm{Zr}$ (wt.\%). Показано, что легирование медью с концентрацией $1.47 \mathrm{wt} . \%$ или соответственно 0.63 at.\% обеспечивает колоссальное упрочнение $\left(\sigma_{0.2} \sim 430 \mathrm{MPa}\right.$, $\left.\sigma_{U T S} \sim 574 \mathrm{MPa}\right)$ при приемлемом уровне электропроводности $46.1 \% \mathrm{IACS}$ и пластичности до 5\%. Предел прочности $\sigma_{U T S}$ данного сплава в состоянии AG_HPT почти в пять раз превышает $\sigma_{U T S}$ сплава $\mathrm{Al}-0.4 \mathrm{Zr}$ в том же состоянии. Показано, что микролегирование медью более эффективно для увеличения прочности по сравнению с $\mathrm{Mg}$ с тем же атомным содержанием в УМЗ сплаве, при этом приводит к меньшему снижению пластичности.

Микроструктурные исследования показали, что после предварительного старения в сплаве $\mathrm{Al}-\mathrm{Cu}-\mathrm{Zr}$ формируются равномерно распределенные в объеме зерен наноразмерные частицы метастабильной фазы $\mathrm{Al}_{3} \mathrm{Zr}\left(\mathrm{Ll}_{2}\right)$ со средним размером $9.3 \mathrm{~nm}$, а также более крупные частицы со средним размером $34 \mathrm{~nm}$ на границах зерен. Обработка ИПДК наряду с формированием однородной 
УМЗ структуры приводит к частичному растворению частиц фазы $\mathrm{Al}_{3} \mathrm{Zr}$ и формированию преимущественно на границах зерен отдельных Сu-содержащих наноразмерных частиц с размерами $20-40 \mathrm{~nm}$. Изменения микроструктуры после старения и последующей ИПДК находятся в хорошей корреляции с изменением электросопротивления.

На базе микроструктурных параметров, определенных методами РСА, ПЭМ и ПРЭМ, а также изменения электросопротивления проведен анализ действующих механизмов упрочнения в состоянии $\mathrm{AG} \_\mathrm{HPT}$ и рассчитаны их вклады в общее упрочнение. Проведенный анализ показал, что добавка меди $\sim 1.5 \mathrm{wt} . \%$ способствует значительному измельчению зерна и, как следствие, увеличивает зернограничное упрочнение. Часть меди остается в твердом растворе и вносит вклад в зернограничное упрочнение. Кроме того, легирование медью приводит к колоссальному дополнительному упрочнению $(\sim 130 \mathrm{MPa})$ в УМЗ сплаве, нетипичному для крупнозернистого состояния и обусловленному, наиболее вероятно, сегрегацией $\mathrm{Cu}$ на границах зерен и формированием нанокластеров $\mathrm{Cu}$.

\section{Благодарности}

Авторы выражают благодарность ресурсному центру „Нанотехнологии“ научного парка СПбГУ и лично Д.В. Данилову за проведение исследований методом сканирующей электронной микроскопии.

\section{Финансирование работы}

Работа выполнена при частичной поддержке Российского фонда фундаментальных исследований (проект № 19-08-00474).

\section{Конфликт интересов}

Авторы заявляют, что у них нет конфликта интересов.

\section{Список литературы}

[1] Astm B941-16, Standard Specification for Heat Resistant Aluminum-Zirconium Alloy Wire for Electrical Purposes, ASTM International, West Conshohocken, PA, 2016.

[2] N.A. Belov, A.N. Alabin, D.G. Eskin, V.V. Istomin-Kastrovskii. J. Mater. Sci. 41, 18, 5890 (2006).

[3] P.H.L. Souza, C.A.S. de Oliveira, J.M. do Vale Quaresma. J. Mater. Res. Technol. 7, 1, 66 (2018).

[4] K.E. Knipling, D.C. Dunand, D.N. Seidman. Z. Metallkd. 97, 3, 246 (2006).

[5] K.E. Knipling, D.N. Seidman, D.C. Dunand. Acta Mater. 59, 3, 943 (2011).

[6] European Committee for Standartization (CEN). En 50183, Overhead Power Line Conductors - Bare Conductors of Aluminium Alloy with Magnesium and Silicon Content. CEN, Bruxelles (2002).
[7] R.Z. Valiev, R.K. Islamgaliev, I.V. Alexandrov. Prog. Mater. Sci. 45, 2, 103 (2000).

[8] H. Miyamoto, K. Ota, T. Mimaki. Scripta Mater. 54, 10, 1721 (2006).

[9] A.P. Zhilyaev, T.G. Langdon. Prog. Mater. Sci. 53, 6, 893 (2008).

[10] R. Reihanian, R. Ebrahimi, N. Tsuji, M.M. Moshksar. Mater. Sci. Eng. A 473, 1-2, 189 (2008).

[11] T.S. Orlova, A.M. Mavlyutov, T.A. Latynina, E.V. Ubyivovk, M.Y. Murashkin, R. Schneider, D. Gerthsen, R.Z. Valiev. Rev. Adv. Mater. Sci. 55, 1, 92 (2018).

[12] T.S. Orlova, T.A. Latynina, A.M. Mavlyutov, M.Y. Murashkin, R.Z. Valiev. J. Alloys Compd. 784, 41 (2019).

[13] T.A. Latynina, A.M. Mavlyutov, M.Y. Murashkin, R.Z. Valiev, T.S. Orlova. Phil. Mag. 99, 19, 2424 (2019).

[14] T.S. Orlova, T.A. Latynina, M.Y. Murashkin, F. Chabanais, L. Rigutti, W. Lefebvre. J. Alloys Compd. 859, 157775 (2021).

[15] А.М. Мавлютов, Т.С. Орлова, Э.Х. Яппарова. ПЖТФ 46, $18,30(2020)$.

[16] Y. Huang, J.D. Robson, P.B. Prangnell. Acta Mater. 58, 5, 1643 (2010).

[17] V.D. Sitdikov, M. Yu Murashkin, R.Z. Valiev. J. Alloys Compd. 735, 1792 (2018).

[18] Y. Nasedkina, X. Sauvage, E.V. Bobruk, M.Yu. Murashkin, R.Z. Valiev, N.A. Enikeev. J. Alloys Compd. 710, 736 (2017).

[19] M. Murayama, Z. Horita, K. Hono. Acta Mater. 49, 1, 21 (2001).

[20] W. Huang, Z. Liu, M. Lin, X. Zhou, L. Zhao, A. Ning, S. Zeng. Mater. Sci. Eng. A 546, 26 (2012).

[21] H. Jia, R. Bjørge, K. Marthinsen, Y. Li. J. Alloys Compd. 697, 239 (2017).

[22] L. Lutterotti, R. Matthies, H.R. Wenk, A. Schultz, J. Richardson. J. Appl. Phys. 81, 2, 594 (1997).

[23] G.K. Williamson, R.E. Smallman. Philos. Mag. 1, 1, 34 (1956).

[24] N.A. Belov, A.N. Alabin, A.R. Teleuova. Met. Sci. Heat Treat. 53, 9, 455 (2012).

[25] K.E. Knipling, R.A. Karnesky, C.P. Lee, D.C. Dunand, D.N. Seidman. Acta Mater. 58, 15, 5184 (2010).

[26] K.E. Knipling, D.C. Dunand, D.N. Seidman. Acta Mater. 56, 1,114 (2008).

[27] A. Paul, T. Laurila, V. Vuorinen, S.V. Divinski. Thermodynamics, Diffusion and the Kirkendall Effect in Solids. Springer Int. Publ., Cham (2014). 529 p.

[28] Y. Miyajima, S.Y. Komatsu, M. Mitsuhara, S. Hata, H. Nakashima, N. Tsuji. Phil. Mag. 90, 34, 4475 (2010).

[29] A.S. Karolik, A.A. Luhvich. J. Phys. Condens. Matter 6, 4, 873 (1994)

[30] H. Jia, R. Bjørge, L. Cao, H. Song, K. Marthinsen, Y. Li. Acta Mater. 155, 199 (2018).

[31] F. Kutner, G. Lang. Aluminum 52, 322 (1976).

[32] G. Sha, A. Cerezo. Acta Mater. 52, 15, 4503 (2004).

[33] Y. Zhang, S. Jin, P. Trimby, X. Liao, M.Y. Murashkin, R.Z. Valiev, G. Sha. Mater. Sci. Eng. A 752, 223 (2019).

[34] N. Kamikawa, X. Huang, N. Tsuji, N. Hansen. Acta Mater. 57, 4198 (2009).

[35] G.E. Totten, D.S. MacKenzie. Handbook of Aluminium. Marcel Dekker, N.Y. (2003). 1310 p.

[36] E.O. Hall. Proc. Phys. Soc. B 64, 9, 747 (1951).

[37] D.B. Witkin, E.J. Lavernia. Prog. Mater. Sci. 51, 1, 1 (2006).

[38] T. Shanmugasundaram, M. Heilmaier, B.S. Murty, V.S. Sarma. Mater. Sci. Eng. A 527, 7821 (2010).

[39] N. Hansen, X. Huang. Acta Mater. 46, 5, 1827 (1998). 
[40] F.R.N. Nabarro, Z.S. Basinski, D.B. Holt. Adv. Phys. 13, 50, 193 (1964).

[41] O.R. Myhr, Ø. Grong, S.J. Andersen. Acta Mater. 49, 1, 65 (2001).

[42] C.B. Fuller, D.N. Seidman, D.C. Dunand. Acta Mater. 51, 16, 4803 (2003).

[43] W. Lefebvre, N. Masquelier, J. Houard, R. Patte, H. Zapolsky. Scripta Mater. 70, 43 (2014).

[44] M.A. Meyers, K.K. Chawla. Mechanical Metallurgy: Principles and Applications. Prentice Hall, N.J. (1984). 762 p.

[45] G. Sha, L. Yao, X. Liao, S.P. Ringer, Zh.Ch. Duan, T.G. Langdon. Ultramicroscopy 111, 500 (2011).

[46] S. Cheng, J.A. Spencer, W.W. Milligan. Acta Mater. 51, 15, 4505 (2003).

[47] V. Yamakov, D. Wolf, S.R. Phillpot, A.K. Mukherjee, H. Gleiter. Nature Mater. 1, 1, 45 (2002).

[48] J.P. Hirth. Met. Trans. 11, 6, 861 (1972).

[49] R.Z. Valiev, N.A. Enikeev, M.Y. Murashkin, V.U. Kazykhanov, X. Sauvage. Scripta Mater. 63, 9, 949 (2010).

[50] J.P. Hirth, J. Lothe. Theory of Dislocations. McGraw-Hill, N.Y. (1968). $780 \mathrm{p}$.

[51] D. Zhao, O.M. Løvvik, K. Marthinsen, Y. Li. Acta Mater. 145, 235 (2018).

[52] E. Nes, B. Holmedal, E. Evangelista, K. Marthinsen. Mater. Sci. Eng. A 410, 178 (2005).

[53] X. Sauvage, N. Enikeev, R. Valiev, Y. Nasedkina, M. Murashkin. Acta Mater. 72, 125 (2014).

[54] Y. Liu, M. Liu, X. Chen, Y. Cao, H.J. Roven, M. Murashkin, R.Z. Valiev, H. Zhou. Scripta Mater. 159, 137 (2019).

Редактор Е.Ю. Флегонтова 